\title{
AGROFORESTRY PRACTICES IN RELATION TO THE AGE AND GROWTH RATE PATTERNS OF Picea smithiana USING MODERN TECHNIQUES OF DENDROCHRONOLGY FROM ISTAK VALLEY OF CENTRAL KARAKORAM NATIONAL PARK (CKNP) GILGIT-BALTISTAN, PAKISTAN
}

\author{
Alamdar Hussain ${ }^{1, *}$, Moinuddin Ahmed ${ }^{2}$, Sher Wali Khan ${ }^{1}$, Haider Abbas ${ }^{3}$, Azhar Hussain ${ }^{4}$ and \\ Qamar Abbas ${ }^{1}$ \\ ${ }^{1}$ Department of Biological Sciences, Karakoram International University, Gilgit, Pakistan; ${ }^{2}$ Department of Botany, \\ Federal Urdu University of Arts, Science and Technology, Karachi, Pakistan; ${ }^{3}$ Department of Agriculture and \\ Agribusiness Management, University of Karachi, Karachi, Pakistan; ${ }^{4}$ Department of Food and Agriculture, \\ Karakoram International University, Gilgit, Pakistan. \\ "Corresponding author's e-mail: alamdar.hussain@kiu.edu.pk,
}

\begin{abstract}
This study was conducted to describe the age and growth rate structure of Picea smithiana from Istak valley of Central Karakoram National Park Gilgit-Baltistan. Thirty two cores were sampled from 16 trees. The mean age of Picea smithiana trees was 222 years while highest age was recorded 434 years. Growth rate ranged from 5 year $/ \mathrm{cm}$ to 17 year/cm. Low significant correlation $(r=0.54, p<0.01)$ was observed between dbh and age while regression between age and growth rate among trees was highly significant $(r=0.76, p<0.001)$. Picea smithiana regression between dbh and growth rates and age and growth rates of seedlings were highly significant. However due to wide variance, dbh was not considered as a good predictor of age. Growth rates of seedling in various periods of time indicated that in the old periods seedling growth was very slow which increased with the passage of time.
\end{abstract}

Keywords: Ecology, forest cover,growth stipulation, dendrochronology, population dynamics.

\section{INTRODUCTION}

Growth is an important factor to understand the management of forest and forest cover (Worrell and Malcolm, 1990a,b). The maximum age of plant species can be strongly affected by the growth stipulation (Castagneriet al., 2013). In the radial growth of trees, annual rings are the sensitive indicator for age and growth (Warming and Pitman, 1985). The vegetation is dynamic because it is constantly degraded by anthropogenic and natural disturbance, which dramatically alter the structure and survival of the forest (Boisvenue and Running, 2006; Abrams and Nowacki, 2008).

The age structure of trees also plays a vital role on population dynamics. The tree age distribution would be helpful for the management of forest and increasing of recruitments (Agren and Zackrisson, 1990). Additionally, fast growth rates and large diameter size of plant species seem clearly to benefit the vigor of trees (Lanner, 2002). Age and growth rates are widely used in silviculture, ecology and forestry.

Hence age and growth rate are the important attribute of the forest structure which are very useful to understand the forest dynamics and improvement of forest management, but there is no reported investigation of age and growth rates carried out from Central Karakoram National Park region so far, therefore this study investigates the age and growth rates of
Picea smithiana forest from Stak valley of CKNP which may be helpful in forest management, ecology and silviculture.

\section{MATERIALS AND METHODS}

Site description:Istak is located in District Skardu, GilgitBaltistan with the coordinates of $35.77^{\circ}$ North and $75.04^{\circ}$ East and an altitude of $2600 \mathrm{~m}$ while the forest belt is distributed on the elevation of $3600 \mathrm{~m}$ above sea level with the slop angle of $20^{\circ}$.This valley is included in the Central Karakoram National Park (CKNP) (Fig. 1). The geographical location of this valley is fascinating, surrounded by Nagar valley in the North, Skardu valley in the South, Shigar valley in the East while Haramosh valley in the West. The valley is accessible by jeep. According to CKNP management 1205 household families live in this valley which is mixed with Balti and Shina language. The valley has unique diversity of flora and fauna. The forest vegetation is mix species of spruce (Picea smithiana), blue pine (Pinus wallichiana) and juniper (Juniperus excelsa). In this area scrub vegetation is dominated by Rosa webbiana, Hippophae rhamnoides, Berberis lycium, Artemisia brevefolium, Thymus linearis, Bistorta, Anaphalis virgata etc. (Hussain et al., 2011). The type of soil is both clay and silt affected with erosion. Sign of illegal cutting and overgrazing was also observed. 
Field methods:During the sampling, standard dendrochronological techniques were applied following Stokes and Smiley, 1968 and Ahmed, 2009. Least disturbed site and tress were selected to obtain core. Thirty two samples from 16 tress were sampled. Two samples were taken from each tree at breast height. Swedish increment borer was used to take the samples from trees while drinking straws were used to preserve the samples during the field trip. GPS was used to record the elevation and location coordinates while dbh measuring tape was used to measure the diameter at breast height (dbh) of each tree.

Mounting and crossdating: In the laboratory, cores were air dried and mounted on wooden strips. These cores were sanded by a sanding machine and using different sand papers until the surface of core sample was clear for visual cross dating. After that visual cross dating under Binocular microscope following the method described by Stokes and Smiley (1968), Fritts (1976), Grissino-Mayer (2001) and Ahmed (2009).

Age and growth rate analysis: Age is calculated on the base of cross dating between cores of the same tree tracing the missing and double ring following Ogden et al. (1987) and Ahmed et al. (2009). The length of the cores was divided by the number of rings present in the core and the growth rate in year per centimeter was calculated following Ahmed (1984) and Ahmed et al. (1990a,b). For the growth rate of seeding in past periods cores were selected which have complete pith. From the pith to the bark side of wood sample $8 \mathrm{~cm}$ was considered to the various past seedlings which were further divided into $2 \mathrm{~cm}$ interval of 4 classes. The growth rate year/cm of each class was calculated by the total rings found in the class divided by the length of class. Histogram and regression was plotted by MS Excel to establish the relationship between age, growth and diameter at breast height.

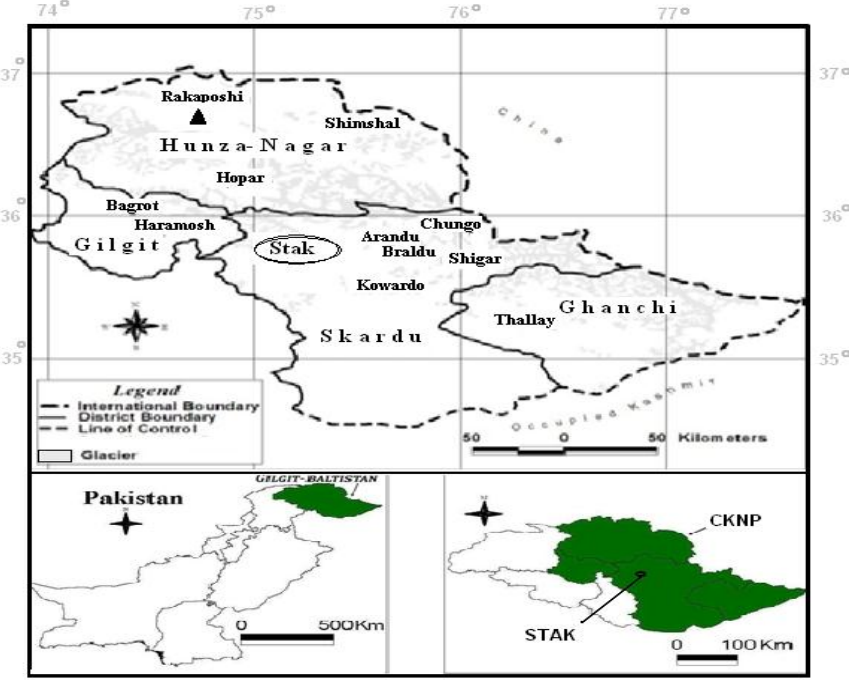

Figure 1. Map of study area, circle shows sampling site (Stak valley of CKNP).

\section{RESULTS}

Age and growth rates of seedlings: The histogram of dbh and mean age are shown in Figure 2. Each class is based on two $\mathrm{cm}$ dbh intervals showing that mean age is increasing with increasing dbh. The mean age of Picea smithiana seedling was 43 year while the mean growth rate was 11 year $/ \mathrm{cm}$. The maximum age of seedling was 126 years. Relation between dbh classes and mean age was highly significant $(r=0.88$, $p<0.001$ ) with wide variance in few points (Fig. 3). The histogram of mean age and growth rates is shown in Figure 4. which shows that growth rates of 2 to $8 \mathrm{~cm}$ dbh classes are almost similar while the regression analysis between these two variables shows highly significant $(r=0.96, p<0.001)$ relation without any variance (Fig. 5).

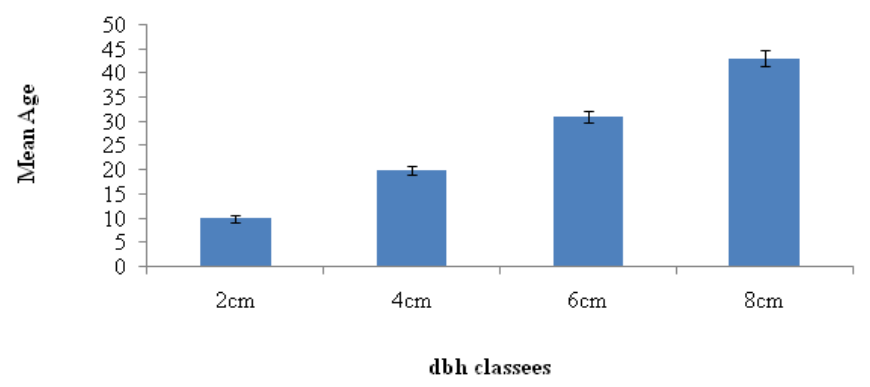

Figure 2.dbh vs age histograms analysis of Picea smithiana seedlings.

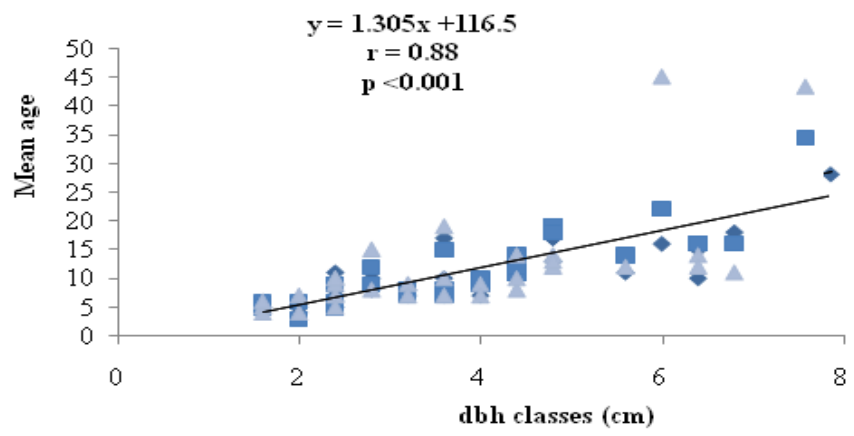

Figure 3. dbh vs age regression analysis of Picea smithiana seedlings.

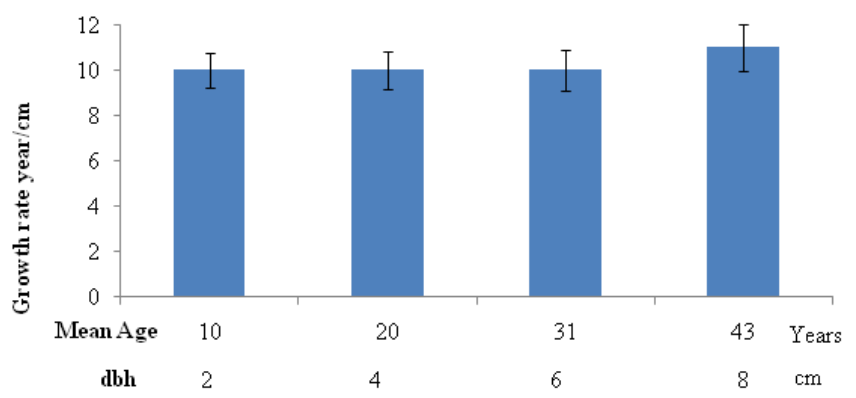

Figure 4. Age vs growth rates histogram analysis of Picea smithiana seedlings. 


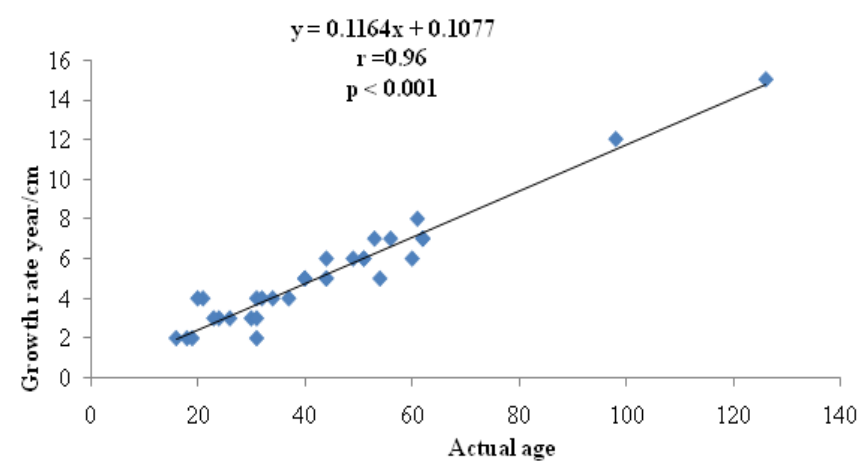

Figure 5. Age vs growth rates regression analysis of Picea smithiana seedlings.

Growth rate of past seedling: An attempt was also made to calculate the growth rates of different periods of past seedlings. Figure 6 shows growth rates of seedling in different periods of past. It was anticipated that past growth rates may reflect the overall situation of the forest in which seedlings were survived. It is shown that around the year $1576 \mathrm{AD}$ the seedlings were growing in most stressed situation (13years $/ \mathrm{cm}$ ). This situation improved around year $1632 \mathrm{AD}$ after 56 years when some of the seedling may be thinned out and rate of growth significantly increased. In the period around $1760 \mathrm{AD}$ and $1851 \mathrm{AD}$ growth rate was almost the same. Similarly, period 1767 to 1789,1809 to 1812 and 1855 to 1870 showed same growth rates but significantly different to previously descended periods. Periods of fastest growth were 1820 to $1827,1848,1852,1872$ while 1902 with significant reduction of growth rates around occurred 1851 AD.

\section{Growth rate of past Seedling}

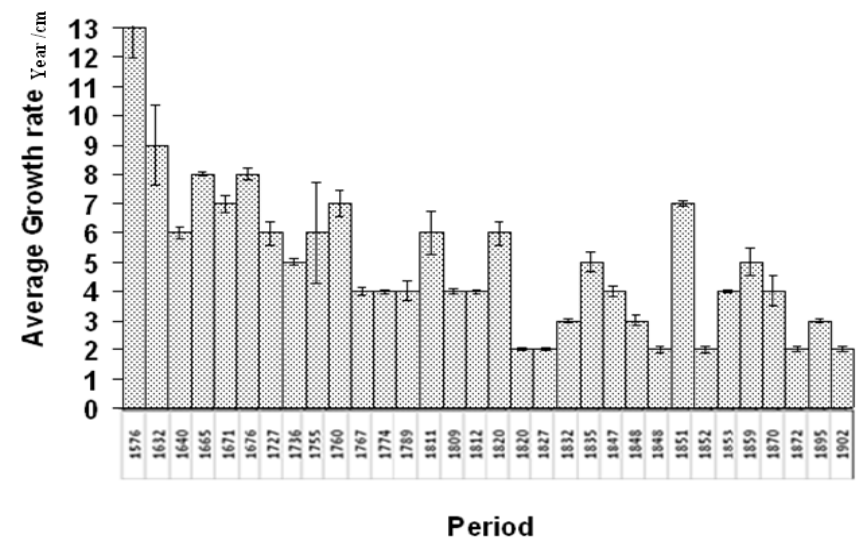

Figure 6. Growth rates of seedlings in various time periods.Each year represents the mean growth rate year/cm of seedlings arround $8 \mathrm{~cm}$ dbh

Age and growth rate of tress: The histogram of dbh and mean age of Picea smithiana trees is presented in Figure 7, which shows that age increases with the increasing of dbh while the regression analysis shows significant relation $(r=0.54, \mathrm{P}$ $<0.01$ ) with wide variance (Fig. 8).

The histogram plot of mean age and growth rates of 9 tree classes are shown in Fig.9 which shows that growth rate almost similar from the small classes to middle classes and decreases in large classes. The growth rates of 10 to $50 \mathrm{~cm} \mathrm{dbh}$ are decreasing while up to $90 \mathrm{~cm}$ dbh reverse was the case. Growth rate decreased with the increased age. It may be due to the old age and natural disturbances. It is observed that 90 $\mathrm{cm}$ dbh tree may attain 400 years. The maximum growth rate was 17 year $/ \mathrm{cm}$ while the mean growth rate was 6 year $/ \mathrm{cm}$. The mean age of Picea smithiana trees was 222 years while the actual age was 434 years. The regression analysis of these variables show highly significant $(\mathrm{r}=0.76, \mathrm{p}<0.001)$ relation with wide variance in few points (Fig.10).

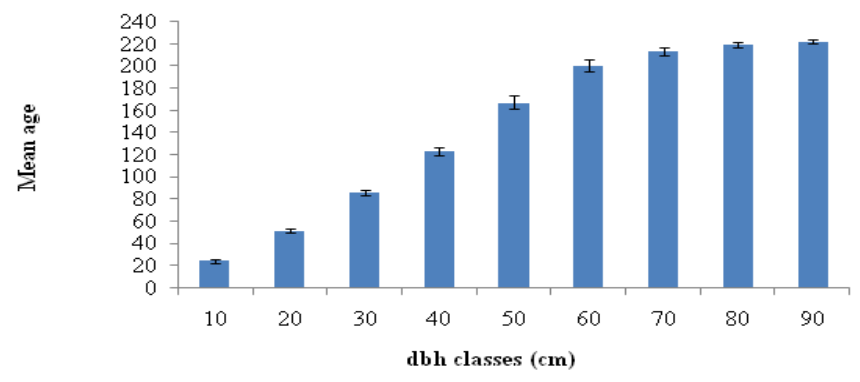

Figure 7.dbh vs age histograms analysis of Picea smithiana.

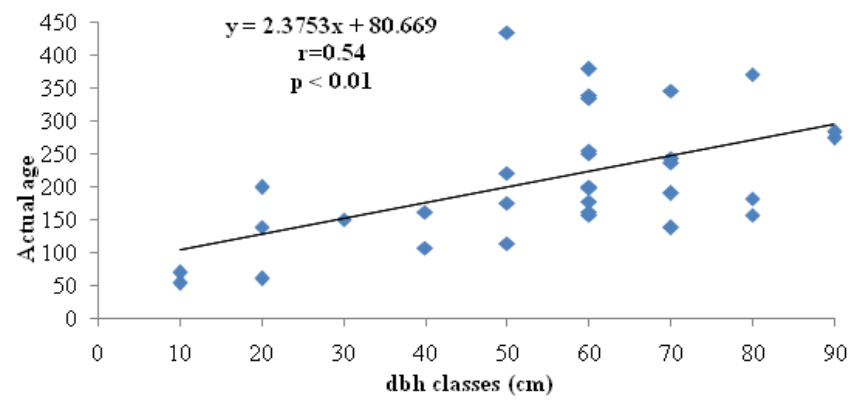

Figure 8. dbh vs age regression analysis of Picea smithiana.

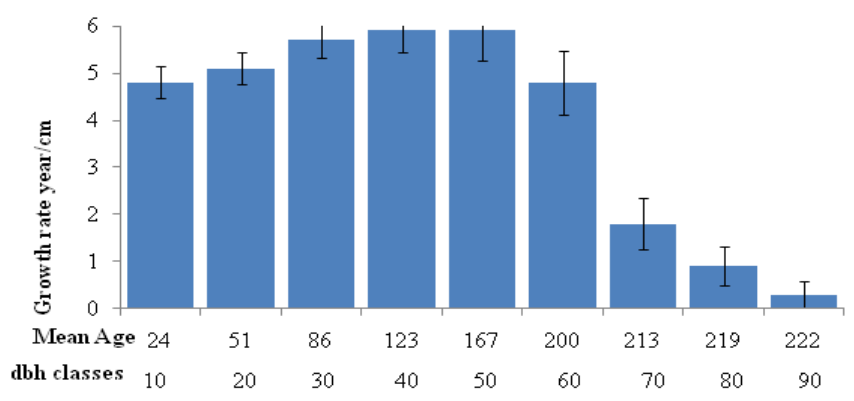

Figure 9. Age vs growth rates histograms analysis of Picea smithiana. 


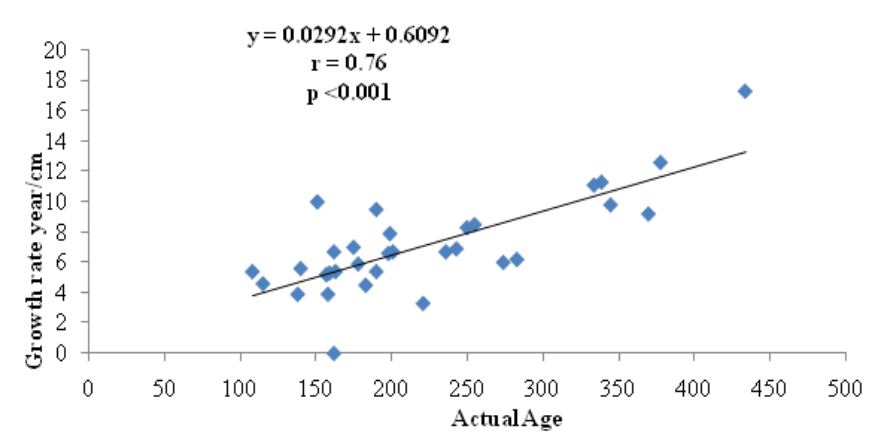

Figure 10. Age vs growth rates regression analysis of Picea smithiana.

\section{DISCUSSION}

Age and growth rates of seedlings: Growth rate is decreasing with the increasing age of seedling. It may be due to anthropogenic disturbances i.e., cutting of trees or overgrazing. It is observed that $8 \mathrm{~cm}$ dbh young tree may attain the age of 126 years. Similar significant results were obtained in correlation analysis between age and growth rates by Syampunganiet al. (2010). The radial growth in seedlings of Pinus gerardiana forest reported 43 years $/ \mathrm{cm}$ while high significant $(\mathrm{r}=0.64, \mathrm{p}<0.001)$ correlation between age and $\mathrm{dbh}$ observed (Ahmed et al., 1991).

The significant relation between dbh and age from planted tree species in Quetta anticipated that in the even age planted species size was similar therefore among these trees age did not vary while in natural and uneven aged population may vary among individuals (Ahmed, 1988). It is also supported that small seedling may have been up to 100 years (Ogden $e t$ al., 1987).

Maximum age (66 years) with 6 dbh classes in Juniperus excels and observed that age varies from seedling to seedling even in a same size class. In the present seedling study, maximum age was 126 years with 2 to 15 year/ $\mathrm{cm}$ growth rate (Ahmed et al., 1989). While the young stage of trees growth rate is fast which gradually decreased with the increasing of age and suggested that the recruitments of trees need special attention of shelter and protection (Wahab, 2011).

The study shows that there is highly significant relationship between dbh and age of seedlings with wide variances. It was also found that seedling classes did not show significant correlation in growth rate. Mode of generation may be an important factor in influencing the growth rate. Therefore, dbh does not prove to be a good indicator of age. It is also concluded that a large diameter stem does not give reliable estimation of age. Due to wide variance, it is not advisable to predict age from dbh in trees. In natural condition, seedlings belong to different regeneration periods and may be subjected to different microclimatic, biological situation or stress. Therefore, growth rates and age varied among the seedlings of the same size.
Growth rate of past seedling:Age varies from seedling to seedling even in same size classes (Ahmed et al., 1989). Age and growth rate varied from species to species, site to site and even trees of same species in a same site. Growth rate of seedling in various periods of time was different in different years. In the past decades growth rate was slow and varied in different years. It is anticipated that in the old period there may be high competition due to no grazing and no deforestation, therefore seedlings growth inhibits but with the passage of time these factors changed which released the rate of growth.Growth rate in the old tress are reduced due to the old age associated with diseases (Ahmed, 2009) and anthropogenic disturbance (Di Filippo et al., 2012). Due to deforestation and overgrazing competition may be diffused and provide a suitable chance for seedling to grow fast. The natural and ecological factors also effect the growth of seedlings which is quite different in the different periods therefore the rate of growth is also change in different periods. Growth rates in the past period of trees can be possibly affected to reach the high age (Castagneriet al., 2013). It is suggested that form $18^{\text {th }}$ century human impact may have increased when logging and cutting of trees increased resulting increased space for better growth of seedlings. Present analysis indicated that even in one stand or natural forest seedling show different rates of growth due to the competition, release of competition, natural disturbance, human disturbance, cutting, fires, overgrazing and harsh or favorable environmental condition. Growth rate helps to clarify the forest dynamics and forest management (Fritts, 1976; Priya and Butt, 1998). Additionally, the growth rate will help in size predictions of the trees and indication of disturbance (Syampunganiet al., 2010). Therefore, this study may be helpful to save this important forest and improve better forest management techniques.

Age and growth rate of tress: The average growth rates 5.7 to 15.3 year/cm and found highly significant $(0.64, \mathrm{p}<0.001)$ relation between age and dbh from Pinus geraradiana forest in Balouchistan (Ahmed et al., 1991) while highest age (112 years) from small dbh tree in Takht-e-sulaimani forest while same age was also recorded in large $\mathrm{dbh}(65 \mathrm{~cm})$ from Ayubia. The growth rate $(4.0$ to 7.1 year $/ \mathrm{cm})$ with no significant relationship between dbh and age of Piceasmithiana and largest $(154 \mathrm{~cm})$ found with small age of 133 years (Wahab, 2008).

In the present study growth rate ranges from 3.9 to 17.3 year/cm while oldest tress (434 years) belonged to $90 \mathrm{~cm} \mathrm{dbh}$ tree. Although growth rate was slow as compare to other findings in Pakistan but the relationship of age/growth rate and dbh/age is within the range of other workers. The current study showed highly significant relationship between actual age and growth rates in Piceasmithiana trees and seedling while the histogram of mean age and growth rate of these trees indicates that growth rate reduces after $50 \mathrm{~cm}$ dbh class which is not an ideal situation. This is the stage of fast growing but 
due to anthropogenic disturbance the growth decreased due to the same reasons and trees was deteriorating in the growing stage. Therefore, we also agree with other workers that diameter is not a good indicator of age due to wide variance. In addition, it may also be concluded that this forest is under anthropogenic disturbances and a special attention should be paid to save this important forest.

Conclusion:The study shows that there is highly significant relationship between $\mathrm{dbh}$ and age of seedlings with wide variances. Growth rate is decreasing with the increasing age of seedling. It may be due to anthropogenic disturbances i.e. cutting of trees or overgrazing It is also found that seedling classes did not show significant correlation in growth rate. Mode of generation may be an important factor in influencing the growth rate. Therefore, dbh does not prove to be a good indicator of age. It is also concluded that a large diameter stem does not give reliable estimation of age. Due to deforestation and overgrazing competition may be diffused and provide a suitable chance for seedling to grow fast. The natural and ecological factors also effect the growth of seedlings which is quite different in the different periods therefore the rate of growth is also change in different periods. It is suggested that the recruitments of trees need special attention of shelter and protection.

Acknowledgement: We are highly obliged to Professor Dr. Syed Shahid Shaukat for useful comments on this draft. We are also thankful to HEC (Project No 20-1806/R\&D/10/149) for financial support during field and lab. work.

\section{REFERENCES}

Abrams, M.D. and G.J. Nowacki. 2008. Native Americans as active and passive promoters of mast and fruit trees in the eastern United States. T. Holo. 18:1123-1137.

Agren, J. and O. Zackrisson. 1990. Age and size structure of Pinus sylvestris populations on mires in central and northern Sweden. J. Ecol. 78:1049-1062.

Ahmed, M. 1984. Ecological and dendrochronological studies on Agathis australis (D. Don) Lindl. (Kauri). Ph.D. Thesis, University of Auckland, New Zealand.

Ahmed, M. 1988. Population structure of some planted tree species in Quetta. J. Pure Appl. Sci. 7:25-29.

Ahmed, M. and A.M. Sarangezai. 1991. Dendrochronological approach to estimate age and growth rates of various species of Himalayan region of Pakistan. Pak. J. Bot. 23:78-89.

Ahmed, M. and A.M. Sarangzai. 1992. Dendrochronological potential of a few tree species from Himalayan Region of Pakistan. J. Pure Appl. Sci. 11:65-67.

Ahmed, M. and J. Ogden. 1987. Population Dynamics of the emergent conifer Agathis australis (D. Don) Lindl. (Kauri) in New Zealand: Population structure and tree growth rates in mature forests. New Zealand J. Bot. 25:217-229.

Ahmed, M., E. Naqi and E.L.M. Wang. 1990a. Present state of Juniper in Rodhmallazi forest of Baluchistan, Pakistan. Pak. J. For. 40:227-236.

Ahmed, M., M. Ashfaq, M. Amjad and M. Saeed. 1991. Vegetation structure and dynamics of Pinus gerardiana forests in Baluchistan. Pak. J. Veg. Sci. 2:199-124.

Ahmed, M., M. Wahab, N. Khan, M.F. Siddiqui, M.U. Khan and S.T. Hussain. 2009. Age and growth rates of some gymnosperms of Pakistan: A dendrochronological approach. Pak. J. Bot. 41:849-860.

Ahmed, M., S.S. Shaukat and A.H. Buzdar. 1990b. Population structure and dynamics of Juniper excelsain Baluchistan, Pakistan. J. Veg. Sci. 1: 271-276.

Ahmed, M. 1989. Tree-Ring chronologies of Abiespindrow (Royle) Spach from Himalayan regions of Pakistan. Pak. J. Bot. 21:118-127.

Boisvenue, C. and S.W. Running. 2006. Impacts of climate change on natural forest productivity evidence since the middle of the $20^{\text {th }}$ century. Glo. Cha. Biol.12:862-882.

Castagneri, D., K.O. Storaunet and J. Rolstad. 2013. Age and growth patterns of old Norway spruce trees in Trillemarka forest, Norway. S. J. For. Res. 28:232-240.

Champion, H., G.S.K. Seth and G.M. Khattak. 1965. Forest Types of Pakistan. Pak. Forest Institute, Peshawar.

Di-Filippo, A., F. Biondi, M. Maugeri, B. Schirone and G. Piovesan. 2012. Bioclimate and growth history affect beech lifespan in the Italian Alps and Apennines. Glo. Cha. Biol.18:960-972.

Fritts, H.C. 1976. Tree Ring and Climate. Oxford Printing Press London; p.576.

Grissino-Mayer, H.D. 2001. FHX2-software for analyzing temporal and spatial pattern in fire regimes from tree rings. Tree Ring Res. 57:115-124.

Khan, A.H. 1968. Ecopathological observation in Trarkhal Forest. Part. 1 Regeneration status of the forest. Pak. J. For. 18:169-228.

Lanner, R.M. 2002.Why do trees live so long? Age. Res. Rev. 1:53:67.

Larson, D.W. 2001. The paradox of great longevity in a short lived tree species. Exp. Geron. 36:651-673.

Ogden, J., G.M. Wardle and M. Ahmed. 1987. Population dynamics of the emergent conifer Agathusaustralis(D. Don) Lindl. (Kauri) in New Zealand. II. Seedling population sizes and gaps-phase regeneration. New Zealand J. Bot. 25:231-242.

Priya, P.B. and K.M. Bhat. 1998. False ring formation in teak (TectonagrandisL.f.) and the influence of environmental factors. For. Ecol. Manage. 108:215-222.

Sheikh, I.S. 1985. Afforestation in Juniper forests of Balochistan. Pak. Forest Inst. Peshawar.

Siddiqui, M.F., M. Ahmed, S.S. Shaukat and M. Ajaib. 2011. Soil and foliar nutrient concentration of conifer species 
in the communities of moist temperate areas of southern Himalayan and Hindu Kush region of Pakistan. FUUAST J. Biol. 1:91-101.

Swati, A.S. 1953. Note on the Juniper forest of Balochistan. Unpublished Report of Balochistan Forest Department, Pakistan.

Syampungani, S., C. Geledenhuys and P.W. Chirwa. 2010. Age and growth rate determination using growth rings of selected miombos woodland species in charcoal and slash and burn re growth stands in Zambia. J. Ecol. Nat. Environ. 2:167-174.

Wahab, M. 2011. Population dynamics and Dendrochronological potential of Pine tree species from
District, Pakistan. Ph.D. Thesis, Federal Urdu University of Arts, Science and Technology, Karachi, Pakistan.

Wahab, M., M. Ahmed and N. Khan. 2008. Phytosociology and dynamics of some pine forests of Afghanistan. Pak. J. Bot. 40:1071-1079.

Worrell, R.and D.C. Malcolm. 1990a. Productivity of Sitka spruce in Northern Britain. 1. The effects of elevation and climate. Forestry 63:105-118.

Worrell, R. and D.C. Malcolm. 1990b. Productivity of Sitka spruce in Northern Britain. 2. Prediction from site factors. Forestry. 63:119-128. 